obachtete Alcoholgährung der Milch auf zu warmes Local zurückführen konnten. Bei kühl gehaltenen Räumen oder rascher Abkïhlung der Milch durch künstliche Mittel war diese Gährung nie aufgetreten. Natürlich ist aber auch zuzufügen, dass in solche Räume, wo Milch aufbewahrt wird, keine alcoholische Gährungshefe gebracht werde, demnach Fernhalten aller anderen Gährungsmischungen, Brodteich, Hefe oder gar Wasser mit gährenden Flüssigkeiten. Wie leicht kann bei dem sonst gegebenen Einfluss von Hefe, die warme, frische Milch, oder durch auffallende Sonnenstrahlen erwärmte, in Gährung gelangen und dient dann als Heerd der Hefe für alle hier aufbewahrte Milch. Ueberfübrung in kalte Localitäten lässt jedoch stets und leicht diese Gährung schwinden.

\title{
Ueber eine Verbindung des Coniins mit Jod.
}

\section{Von Harry R. Bauer. \\ (Vorläufige Mittheilung.)}

Ueber die Einwirkung des Jods auf Coniin fand ich in den grösseren Handbüchern weiter Nichts als die Angabe von Geiger*), dass Jod beim Zusammenreiben mit wasserfreiem Coniin unter gleichzeitiger Bildung von dicken weissen Nebeln eine anfangs blutrothe, später olivengrüne und extractartige, in Wasser zum Theil lösliche Masse bilde.

Bly th**) macht Angaben über das Verhalten von weingeistiger Jodlösung gegen weingeistige Coniinlösung. Bl. giebt an, dass Jodlösung mit Coniin eine gelbe', rasch verschwindende Trïbung erzeuge. Beim Verdunsten dieser Lösung im Vacuum bleibt bräunliche Mutterlauge neben Krystallen zurück, die sich leicht in Wasser, Weingeist und Aether lösen.

Die Eigenschaften oder Zusammensetzung dieses so entstandenen Körpers fand ich nirgends angegeben. ***)

*) Geiger Mag. f. Pharm. XXXV, 72,259.

**) Blyth Quart. J. Chem. Soc. London I, 545.

***) G me lin Handbuch d. Chem. VI, 525, Gerhardt. Org, Chem. IV, 6 
Ich versuchte zunächst mir diesen Körper wo möglich im krystallinischen Zustande zu verschaffen, und operirte wie folgt. Ich löste Coniin in Alkohol, versetzte tropfenweise mit weingeistiger Jodlösung, jedoch nicht mit so viel Jodlösung, dass das Coniin vollständig ausgefällt wurde, sondern noch ein Ueberschuss in Lösung blieb. Es entstand anfangs eine Trübung, die jedoch bald wieder verschwand. In gelinder Wärme wurde der Alkohol abgedunstet und es blieb eine schwach gelblich gefärbte Masse zurück, intensiv nach Coniin riechend, leicht löslich in Wasser, Alkohol, Aether und Chloroform, nicht löslich in Benzol, kaltem wie kochendem, spurenweise nur löslich in Schwefelkohlenstoff.

Der schwach gelb gefärbte Rückstand, in Wasser gelöst, lässt nach wochenlangem Stehen über Chlorcalcium Krystalle niederfallen, vollkommen ausgebildete Octaëder von ziemlicher Grösse, schwach gelb gefärbt, nach Coniin riechend. Die Krystalle lassen sich auch aus Aether umkrystallisiren, man erhält in diesem Falle sternförmig vereinigte Gruppen.

Die Krystalle wurden im Vacuum vollständig getrocknet und dann deren Analyse unternommen. Da sich die Verbindung nach einem Vorversuche ausserordentlich leicht mit Silbernitrat umsetzte, so glaubte ich bei der Jodbestimmung keinen Schwierigkeiten zu begegnen.

Die nächsten Bestimmungen zeigten mir jedoch, dass die Fällungsmethode mittelst Silbernitrat in diesem Falle unbrauchbar war.

$$
\begin{array}{lll}
\text { I. } & 56,372 \% & \text { Jod. } \\
\text { II. } & 58,103 \% & \text { erhalten. }
\end{array}
$$

Tie Bestimmungen differiren zu sehr, als dass ich sie benutzen könnte. Die zweite Bestimmung fiel für die theoretisch berechnete Menge zu hoch aus, vielleicht erklärlich dadurch, dass dem Jodniederschlage jodsaures Silber beigemengt war.

$$
\begin{aligned}
& 3\left(\mathrm{C}^{8} \mathrm{H}^{15} \mathrm{~N}\right)^{3} \mathrm{HJ}, \mathrm{J}^{3}+12 \mathrm{NAg} \theta^{3}+6 \mathrm{H}^{2} \theta= \\
& 9 G^{8} \mathrm{H}^{15} \mathrm{~N} . \mathrm{NH} \theta^{3}+11 \mathrm{AgJ}+\mathrm{JAg} \theta^{3}+3 \mathrm{NH} \theta^{3}
\end{aligned}
$$

Ich versuchte nun mittelst der Wagner'schen Methode zum Ziele zn gelangen. Doch auch diese Methode erwies 
sich wegen des präexistirenden Gehaltes der Verbindung an Jodwassersäure als untauglich.

Ich versuchte es hierauf mit einer Methode, die $\mathrm{Hilger*}$ zu ähnlichen Bestimmungen mit bestem Erfolge anwandte.

H. verbrannte die Verbindung mit chlorfreiem Kalke, aus Marmor durch Glïhen dargestellt. Die Verbrennung wurde in einer 50 Centimeter langen Röhre vorgenommen. Nach der Verbrennung wurde der Kalk in Salpetersäure gelöst, einige Zeit schweflige Säure durchgeleitet zur Zersetzung von allenfalls vorhandenem jodsaurem Salze und nun die Lösung mittelst Silbernitrat gefällt.

Hilge ${ }^{* *}$ ) erhielt nach dieser Methode ganz brauchbare Resultate, doch glaube ich, dass die Methode, um genaue Resultate erwarten zu können, eingeübt sein muss.

Ich entschloss mich nun endgültig, die Carius's che Methode, ***) die mir in den meisten Fällen als bei weitem die brauchbarste erscheint, anzuwenden. Danach wird die Substanz mittelst Salpetersäure und Silbernitrat in geschlossenem Rohre erbitzt.

Da ich diese Methode schon unzählige Male anwandte, so kann ich wobl mit Recht behaupten, dass sie vor allen anderen zur Bestimmung des Jodgehaltes in organischen Substanzen anwendbar ist; die nachfolgenden analytischen Belege basiren auf dieser Methode:

$$
\begin{aligned}
\text { I. } & \mathbf{5 7 , 3 5 2} \\
\text { II. } & \mathbf{5 7 , 4 1 2} \\
\text { III. } & \mathbf{5 7 , 2 7 3} \\
\text { IV. } & \mathbf{5 7 , 3 7 2} \\
\text { V. } & \mathbf{5 7 , 4 3 2} \\
\hline \text { Mittel: } & \mathbf{5 7 , 3 7 0 \%}
\end{aligned}
$$

*) Hilger, Ueber Verbindungen des Jods mit Pflanzenalkaloiden. Würzburg 1869 ,

**) u. a. 0.31 .

***) Carius, Analyt. Zeitscbrift X, 103. 
Mithin in der fraglichen Verbindung

$$
\begin{gathered}
57,370 \text { Jod. } \\
42,630 \text { Coniin. } \\
\hline 100,000 \\
57,370: 127,1=0,368 \\
42,630: 125,=0,340
\end{gathered}
$$

Das Verhältniss des Jods zum Coniin ist somit wie 4:3. Für die Formel $3\left(G^{8} \mathrm{H}^{15} \mathrm{~N}\right)^{9} \mathrm{HJ}, \mathrm{J}^{3}$ berechnet sich der Jodgehalt zu $57,466 \%$ Jod.

Diese aufgestellte Formel trägt daher den analytischen Ergebnissen vollständig Rechnung. Dass die Verbindung Jodwasserstoffsäure enthalte, beweist hinlänglich das Verhalten gegen Natriumbyposulfit und gegen metallisches Quecksilber. Schüttelt man nämlich die Verbindung mit metallischem Quecksilber, so entsteht eine Doppelverbindung, wobei nur 3 Atome Quecksilber aufgenommen werden.

Nach all' dem kömmt der Verbindung die Formel

$$
\begin{aligned}
& G^{8} H^{15} \mathrm{~N}-\mathrm{J}-\mathrm{J}-\mathrm{C}^{8} \mathrm{H}^{15} \mathrm{~N} \\
& \boldsymbol{G}^{8} \mathrm{H}^{15} \mathrm{~N}-\mathrm{J}-\mathrm{J} \mathrm{H}
\end{aligned}
$$

zu, und wäre dieselbe jodwasserstoffsaures Coniintrijodid.

Ich bin gerade beschäftigt, andere Verbindungen des Jods mit Conïn, dessen Umsetzungen zu studiren, behalte mir daher weitere Mittheilungen über diesen Gegenstand vor.

München im Mai 1874.

Prof. Dr. Wittsteins Laboratorium.

\section{Ueber die Aufbewahrung von Infusen, Decocten und Nahrungsmitteln unter Baumwolle.}

Von Prof. Aug. Almén in Ũsala.

Mittheilungen aus der Scandinavischen pharmaceutischen Literatur.

Von Prof. Tb. Husemann in Göttingen.

Während mehrerer Jahre hindurch fortgesetzter, mehr oder minder genauer Versuche, Nahrungsmittel und andere organische Stoffe, welche leicht verderben oder faulen, aufzu- 